\title{
O USO DO GEOGEBRA COMO FERRAMENTA AUXILIAR PARA ESTUDO DA RETA TANGENTE A UM GRÁFICO
}

\author{
Thiago Beirigo Lopes - IFMT - thiagobeirigolopes@yahoo.com \\ Leniedson Guedes dos Santos - UFOB - leniedson@ hotmail.com
}

\begin{abstract}
Resumo: Muitas pesquisas têm sido realizadas na área de Educação Matemática descrevendo as dificuldades encontradas pelos discentes em compreender os conceitos de Cálculo Diferencial e Integral. Nesse sentido, este trabalho tem como objetivo apresentar a análise de uma aula diferenciada, desenvolvida como atividade curricular, realizada com os 32 discentes do $3^{\circ}$ semestre do curso de Bacharelado em Agronomia do Instituto Federal de Mato Grosso - IFMT - Campus Confresa, a qual visou possibilitar a estes discentes um aprofundamento dos conceitos desenvolvidos no estudo de reta tangente na disciplina de Cálculo I. A metodologia de aula proposta foi aplicada pelo docente titular da disciplina nas dependências do laboratório de informática da referida instituição de ensino, durante o $1^{\circ}$ semestre do ano de 2016. Nosso objetivo era o de avaliar a interação dos discentes em uma aula onde fosse possível interagir com o gráfico e a reta tangente a um de seus pontos. A aula consistiu em atividades utilizando o software GeoGebra, objetivando a construção do conceito de derivada no ponto por meio de simulações gráficas. Foi percebida durante a realização da aula a curiosidade aguçada dos discentes com respeito as construções gráficas o que evidencia uma maior disposição à aprendizagem.
\end{abstract}

Palavras-chave: Cálculo Diferencial. Reta tangente. TIC. GeoGebra.

\section{GEOGEBRA USE AS TOOL AUXILIARY FOR STUDY OF RETA TANGENT TO A GRAPHIC}

\begin{abstract}
Many studies have been conducted in mathematics education area describing the difficulties encountered by students in understanding the concepts of Differential and Integral Calculus. In this sense, this work aims to present the analysis of a different class, developed as a curricular activity, carried out with 32 students of 3rd semester of the Bachelor in Agronomy from the Federal Institute of Mato Grosso - IFMT - Campus Confresa, which aimed enable these students a deepening of the concepts developed in the tangent line study in the calculation of discipline I. the proposed class methodology was applied by the titular teacher of the subject in the computer lab facilities of that educational institution, during the 1st half of the year 2016. Our goal was to evaluate the interaction of students in a class where they could interact with the chart and the tangent line to one of his points. The class consisted of activities using the GeoGebra software, aiming to build the concept of derivative at point through graphic simulations. Was perceived during the course of the class piqued curiosity of students with respect to the graphic constructions which shows a greater willingness to learning.
\end{abstract}

Keywords: Differential Calculus. Tangent. ICT. GeoGebra.

\section{Introdução}

$\mathrm{Na}$ contemporaneidade do ensino superior das ciências exatas ainda se encontra destacada a predominância de uma educação tradicionalista baseada no modelo cartesiano, reducionista e linear, onde a metodologia de ensino se desenvolve sob uma 
exposição formal e discursiva dos conteúdos pelo docente (MELLO e MELLO, 2003). Em uma tentativa de resumir, podemos perceber que os discentes ainda estão limitados ao espaço de suas mesas e cadeiras, sendo-lhes exigidas apenas as habilidades de memorização e reprodução mecânica. Hoje é predominante o ensino de derivada onde a ferramenta básica é a tabela de derivadas, onde se trabalha exclusivamente com a "conversão" de uma função em sua derivada, sem explicitar o motivo dos resultados ou, menos ainda, sua utilidade em um modelo prático.

O demonstrativo da não-aprendizagem, comprovadas pelos índices de desistência e reprovação em cálculo diferencial na instituição de realização do trabalho, assinalam para a ineficiência pedagógica desse modelo desprovido de sentido. Sob a ótica da formação global do discente, a abordagem tradicional de educação também se mostra insuficiente, pois não colabora com o pleno desenvolvimento das características exigidas pela sociedade atual em relação aos futuros profissionais: criatividade, raciocínio crítico, entre outras. Os valores da educação tradicional, baseados no saber do docente, se fazem opostos aos valores emergentes da sociedade que começa a tornar legítimo o saber, o saber fazer e o saber ser.

Sobre este modelo pedagógico e sua afinidade com o processo de ensino da matemática é conveniente o que dizem Gravina e Santarosa (1999), onde afirmam que o processo de pesquisa vivenciado pelo matemático profissional destaca a forma não adequada dessa abordagem. Na pesquisa matemática, o conhecimento é construído a partir do processo de muita investigação e exploração, sendo a formalização simplesmente o coroamento deste trabalho, que finaliza na escrita formal e organizada dos resultados obtidos.

As educações matemáticas nos cursos superiores se encontram na eminente necessidade de reestruturação das suas metodologias pedagógicas. É a partir dessa problemática e da possibilidade de desenvolvimento e avaliação de novas técnicas pedagógicas com base na teoria construtivista de Piaget (2003) que elaboramos uma aula sob os moldes construtivistas, onde o docente é orientador da atividade, assim sendo o discente autônomo de seu próprio saber (FREIRE, 2000).

Com a intenção de abranger essa expectativa no ensino de derivadas, o presente trabalho se configura como um relato de experiência realizado a partir da modelagem matemática da função derivada e aplicação do software GeoGebra para estudo da variação dos coeficientes das retas tangentes aos pontos do gráfico. Portanto, o objetivo principal desse trabalho é de avaliar a interação dos discentes em uma aula onde fosse possível interagir com o gráfico e a reta tangente a um de seus pontos, assim utilizando meios para a melhoria da aprendizagem sobre a essência da derivada que é a variação do coeficiente angular da reta tangente aos seus pontos.

É importante ressaltar que o Cálculo Diferencial e Integral é uma das disciplinas mais tradicionais do ensino superior de ciências exatas e base referencial para a compreensão do desenvolvimento científico e tecnológico desde que foi sugerida por Newton (1646-1727) na Inglaterra e Leibnitz (1646-1716) na Alemanha, a mais de trezentos anos. Apesar de sua grande importância e atualidade como conhecimento, o ensino do Cálculo Diferencial e Integral, ainda mantém sua estrutura original, sendo considerada uma das disciplinas onde se apresentam as maiores dificuldades de aprendizado quando do ingresso no nível superior (BOYER, 2012). 


\section{Referencial teórico}

Essa proposta metodológica está alicerçada em referenciais teóricos de enfoque construtivista, baseados na teoria do desenvolvimento cognitivo de Jean Piaget (2003). Nessa percepção, para se haver ensino ${ }^{1}$ é necessário tê-lo como um procedimento em que os discentes participam ativamente da construção seu próprio conhecimento, experimentando-o e fazendo parte do seu processo de síntese.

Os estudos de Piaget (PIAGET e INHELDER, 2011) nos mostram que o desenvolvimento das funções cognitivas se dá em uma contínua evolução das estruturas mentais, que é resultante de um processo de interação entre o sujeito que procura compreender e o mundo no qual está submerso. Buscando assim, resolver aos questionamentos que esse mundo lhe incita. Por meio de suas próprias ações, ele edifica seu pensamento ao mesmo tempo em que estabelece ligações com os objetos ao seu redor.

Trazendo a explanação para o ensino de Cálculo Diferencial e Integral, Ávila (2006) considera prejudicial o ensino de derivadas normalmente ser iniciado por um extenso e tedioso capítulo sobre limites, sem necessidade para que assim o seja. Geralmente no ensino dessa disciplina ocorre de a abordagem desse conteúdo ser pouco intuitiva, caracterizada por atividades com excesso de repetição por meio da manipulação algébrica e pouco significativas para os discentes. Ele afirma que "devemos enfatizar que a derivada foi inventada há mais de três séculos; e, juntamente com o conceito de integral, ela é o alicerce de toda a ciência e tecnologia dos últimos trezentos anos" (ÀVILA, 2006, p. 37).

Nesse mesmo contexto, em seu trabalho realizado com 28 dissertações e teses que abordam sobre ensino de Cálculo Diferencial e Integral, Pagani e Allevato (2014) perceberam com este mapeamento que as dificuldades existentes no ensino de Cálculo Diferencial e Integral, evidenciadas pelos altos índices de reprovação nos cursos iniciais de Cálculo, constituem a principal motivação para realização dos trabalhos analisados. "Este problema tem sido enfrentado em diversas Universidades com o oferecimento de uma disciplina de Pré-Cálculo" (ROJAS, RITTO e BARBOSA, 2008, p. 15)

Desse modo, incentivar, ou até mesmo descobrir, a curiosidade e motivação nos discentes não é uma tarefa fácil de ser executada com êxito. De acordo com Balancho e Coelho (2001), conseguimos motivar os discentes no momento em que apresentamos as atividades curriculares de ensino como atividades ou experiências interessantes ao discente. Para isso, é fundamental cativá-los para as aulas, principalmente para as aulas que envolvam os conteúdos de Matemática.

Uma das principais dificuldades encarada pelos docentes de matemática é propor atividades que sejam atrativas para os discentes e, ao mesmo tempo, não desviem das competências fundamentais específicas de cada nível de ensino (SOUSA, 2014). Dessa maneira as Tecnologias em Informação e Comunicação (TIC) são instrumentos diários dos discentes e, por conseguinte, são ferramentas que naturalmente sabem manusear com propriedade. A questão que se acata é: 'Porque não utilizamos em sala de aula essas ferramentas com as quais os nossos discentes sabem trabalhar com tanta intimidade?'.

As tecnologias não estão deixando obsoletos nossos professores e as escolas, porém, estão redefinindo os seus papéis. Certamente, uma proposta que esteve,

\footnotetext{
${ }^{1}$ Em todo o texto evitamos utilizar o termo dicotômico ensino-aprendizagem, pois acreditamos que não há ensino sem aprendizagem, ou seja, não se cabe desassociar a aprendizagem como resultado do ensino. Acreditamos que se não houve aprendizagem, então consequentemente não houve ensino. Já a recíproca não é válida, pois pode haver aprendizado sem haver tido o ensino.
} 
e está em muitas de suas práticas, extremamente centrada no professor, na transmissão de conteúdos, poderá, num novo ambiente, se desenvolver centrada nos processos de aprendizagem, no desenvolvimento de competências e habilidades (cognitivas, afetivas, interpessoais etc.) do estudante, considerado como sujeito ativo no processo de aprendizagem. (ROJAS, RITTO e BARBOSA, 2008, p. 16).

Introduzir essas ferramentas em sala de aula poderá ser um fator essencialmente motivante para os discentes ficarem suficientemente interessados para participarem da aula de Cálculo Diferencial e Integral (COSTA e JÚNIOR, 2007). As TIC também proporcionam estímulos visuais que delineiam e favorecem uma melhor compreensão dos conceitos matemáticos. Segundo Silva (2015), o software GeoGebra, muito usado em geometria dinâmica, é uma ferramenta atraente e facilitadora no ensino sobre funções quadráticas. Com ele o aprendizado se torna mais interessante e faz com que os discentes compreendam significativamente o conteúdo.

Na construção dos gráficos das funções e suas derivadas, o GeoGebra facilita o ensino por não necessitar de recorrer aos extensivos métodos algébricos que conhecemos para essa construção. Mesmo acreditando que esses métodos algébricos sejam importantes para a formação do discente, não podemos crer que um ensino baseado apenas na construção não dinâmica de gráficos de funções quadráticas seja o ideal.

Assim, para atuar no ensino atualmente, é imprescindível ao ser docente proporcionar um ambiente educativo onde "ao discente deve ser dada a oportunidade de falar com franqueza, expondo as suas dúvidas e dificuldades, sem receio de ser avaliado" (BALANCHO e COELHO, 2001, p. 47). É essencial para a aprendizagem significativa constituir-se como a essência do processo de aprendizagem, uma vez que é significativo por definição, basilar na transformação dos significados lógicos dos materiais de aprendizagem, potencialmente significativos, em significados psicológicos (AUSUBEL, 2003; AUSUBEL, NOVAK e HANESIAN, 1980).

\section{Material e métodos}

Para essa experiência foi escolhido o $3^{\circ}$ semestre da turma do curso Bacharelado em Agronomia do Instituto Federal de Mato Grosso - Campus Confresa. A escolha dessa turma se deve ao fato de ter discentes de várias cidades da Região Araguaia-Xingu e o curso ser de período integral. Desse modo os 32 discentes, teoricamente, se dedicam exclusivamente aos estudos. O lugar para essa atividade foi o laboratório de informática que possui 20 computadores com o sistema operacional baseado em linux (uma vantagem do GeoGebra é poder ser utilizado nos dois sistemas operacionais, windows e linux), assim tendo que ficar no máximo dois discentes compartilhando o mesmo computador, propiciando dessa maneira a socialização da experiência, no mínimo, entre esses dois discentes, com duração de 3 aulas (2:30 horas). Destacamos que, anteriormente à aplicação no GeoGebra no laboratório de informática, foram ministradas aulas como de costume, somente com pincel, quadro branco e apostila, sendo os discentes ensinados a encontrar a derivada através da recorrente tabela.

Recentemente um entrave no uso dessa metodologia seria a indisponibilidade de computadores para que os discentes pudessem manipular a interface do GeoGebra (Figura 1), mas tanto discentes como as escolas, em grande número, já possuem acesso a esses tipos de recursos de multimídias. O desafio maior está em fazer com que eles utilizem esses recursos como facilitadores da aprendizagem, pois tanto docentes como discentes costumeiramente usam esses recursos somente para jogos, redes sociais e entretenimento 
sem fins educativos. A curiosidade faz com que os discentes possam se surpreender e tornar mais proveitoso do que levar funções para a aula e pedir simplesmente que observem seus gráficos (SILVA, 2015).

Diante dos computadores, os discentes experimentaram construir livremente vários tipos de gráficos e, de modo espontâneo, o gráfico da derivada juntamente com a função primitiva para tentarem entender seu significado gráfico. Tentaram funções polinomiais, trigonométricas, logarítmicas, exponenciais e todas outras que haviam aprendido a "transformar" em derivada.

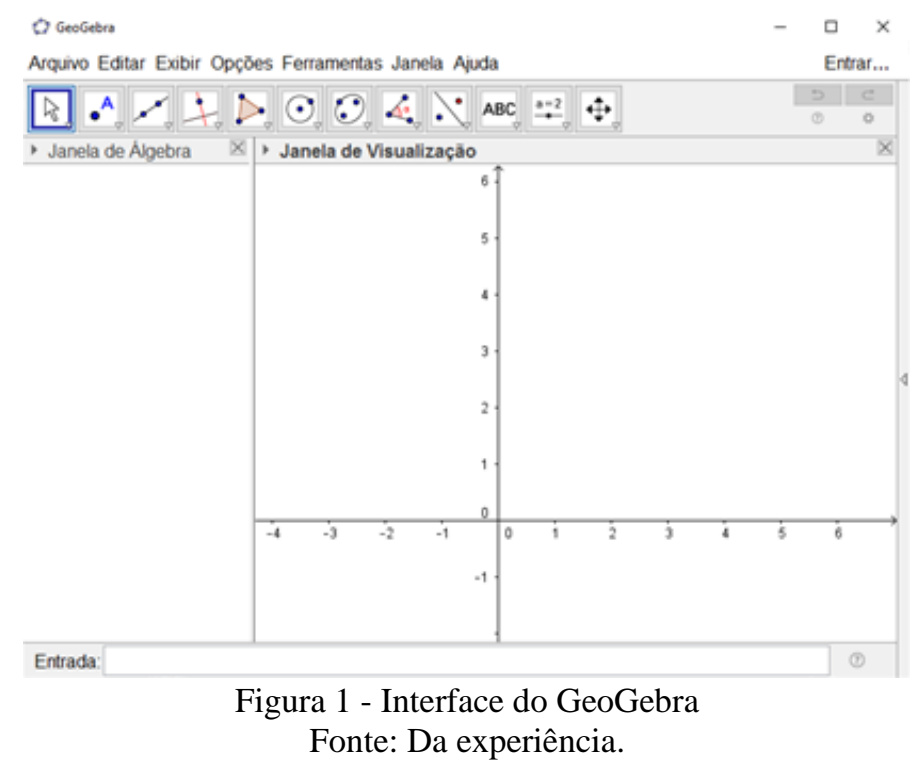

Para experimentar graficamente o que ocorre com a definição de derivada, recomendamos que construíssem o gráfico da função quadrática $f(x)=x^{2}-4 x+3$ e calculassem em seus cadernos, por meio da fórmula $y-y_{0}=f^{\prime}\left(x_{0}\right)\left(x-x_{0}\right)$ estudada anteriormente, a reta tangente ao gráfico em quatro pontos $A=(0,3), B=(1,0), C=$ $(2,-1)$ e $D=(3,0)$, conforme a Figura 2 . Os resultados das retas tangentes foram, respectivamente, $y+4 x=3, y+2 x=2, y=-1$ e $y-2 x=-6$.

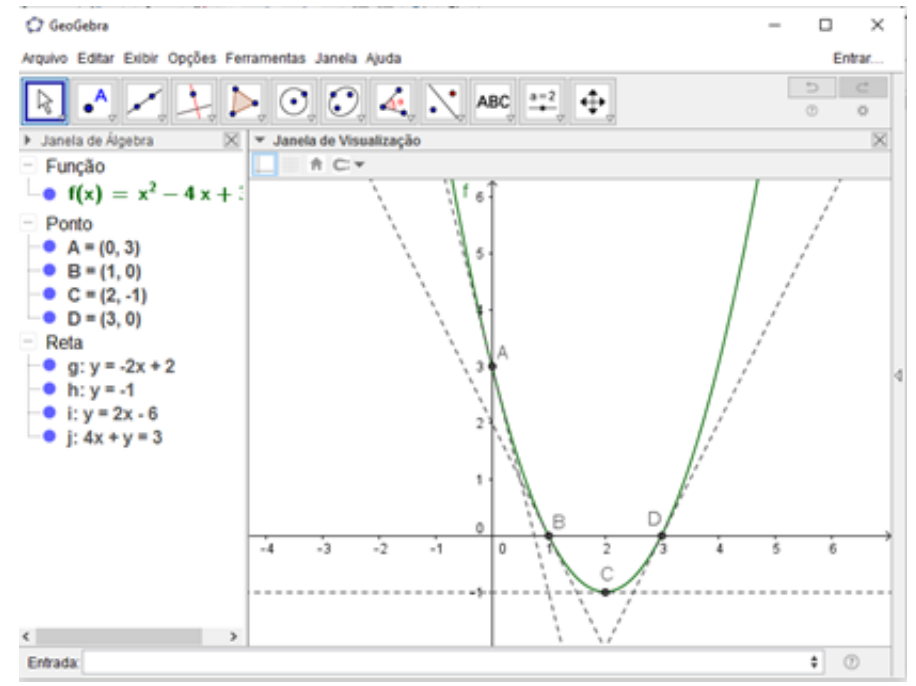

Figura 2 - Plotagem de $f(x)=x^{2}-4 x+3$ com as retas tangentes Fonte: Da experiência. 
Após os discentes satisfazerem todas as suas curiosidades sobre a interface do GeoGebra com a sugestão de função para calcular a reta tangente nos pontos dados, foi solicitado que os discentes sugerissem uma nova função para fazermos o cálculo de algumas retas tangentes ao gráfico.

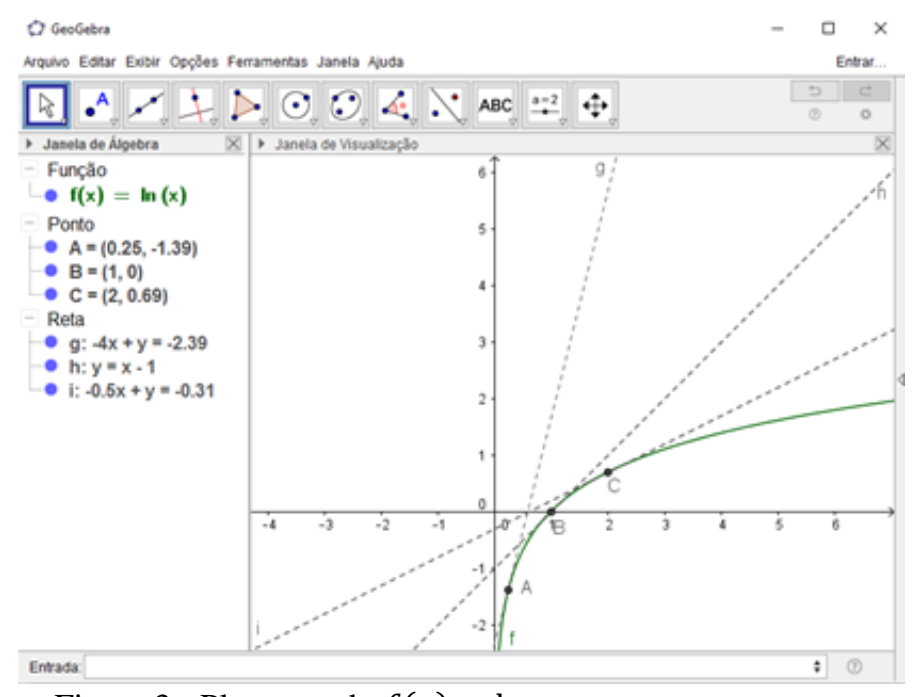

Figura 3 - Plotagem de $f(x)=\ln x$ com as retas tangentes Fonte: Da experiência.

Em outro momento, analisamos as os gráficos das funções com sua respectiva derivada. Foi experimentado pelos discentes plotar o um gráfico de sua escolha e, juntamente, plotar o gráfico de sua derivada para tentar observar relações entre o gráfico da função primitiva e o coeficiente angular. Posteriormente foi sugerido que os discentes colocassem e retas tangentes no gráfico da função primitiva para uma melhor performance na procura das tais relações. Na Figura 4 temos um exemplo da atividade que foi realizada.

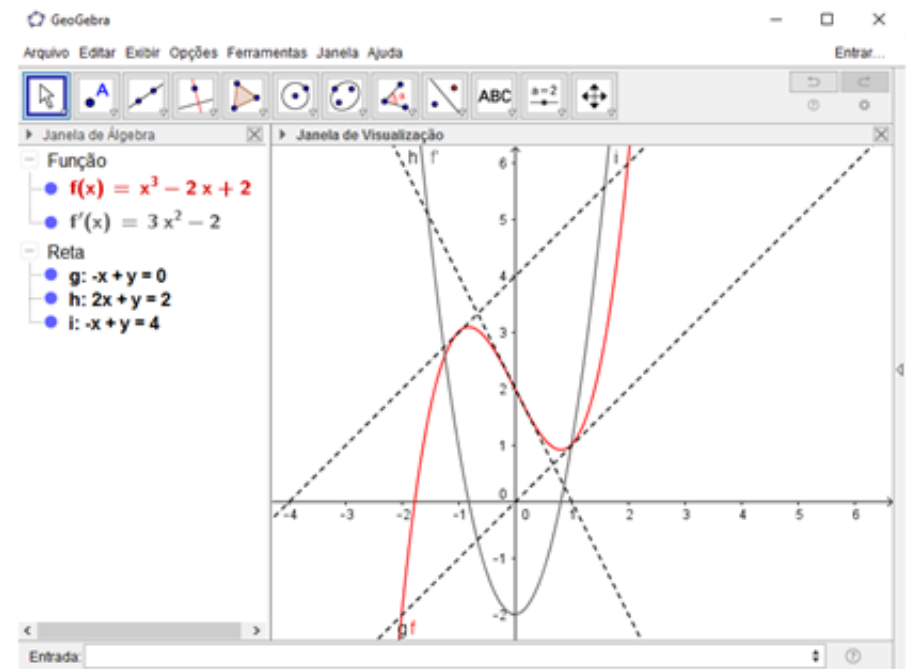

Figura 4 - Plotagem de $f(x)=x^{3}-2 x+2, f^{\prime}(x)=3 x^{2}-2$ e as retas tangentes em abscissa $-1,0$ e 1 Fonte: Da experiência.

Porém não houve uma constituição de relações entre os coeficientes angulares das retas tangentes e a função derivada $f^{\prime}(x)$, tendo o docente que passar para a próxima atividade que consistiu em utilizar os controles deslizantes para variar os valores da abscissa $x$ para fazer a reta tangente "deslizar pelo gráfico". Utilizando a mesma função 
da Figura 4, $f(x)=x^{3}-2 x+2$, nomeamos a barra deslizante como variável $x_{0}=[0,2]$ e a função reta tangente, baseada na equação da reta tangente, $y-\left(x_{0}{ }^{3}-2 x_{0}+2\right)=$ $\left(3 x_{0}{ }^{2}-2\right)\left(x-x_{0}\right)$ teremos o que almejamos com o GeoGebra, conforme a Figura 5.

Nessa atividade foi proposital deixar que os discentes façam a função da reta tangente sem recursos do GeoGebra sobre derivadas, para poder dar maior significado ao coeficiente angular que corresponde a $f^{\prime}\left(x_{0}\right)$ sendo $x_{0}$ o ponto da abscissa dessa reta tangente.

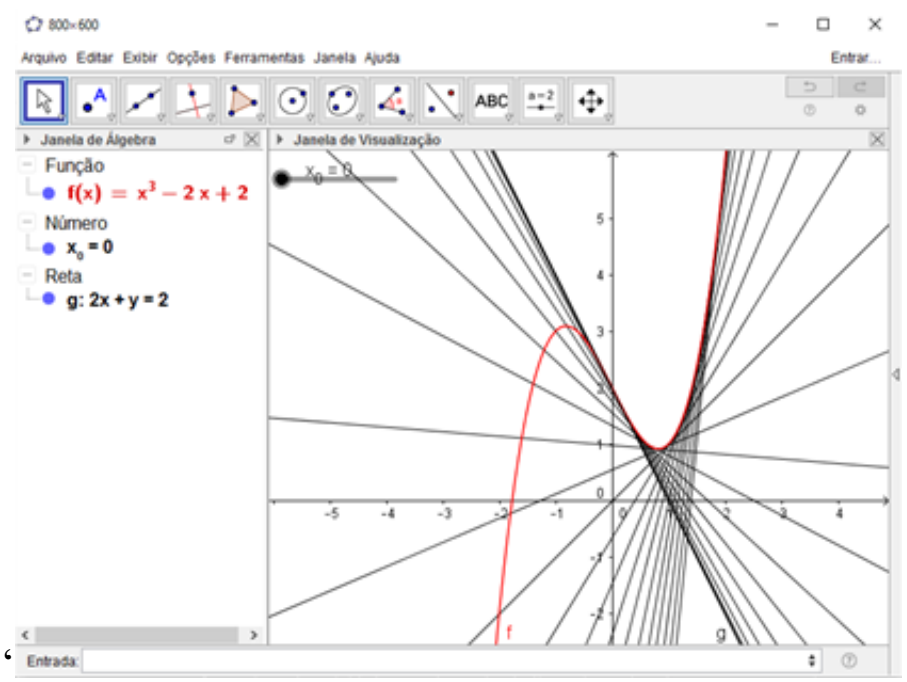

Figura 5 - Plotagem de $f(x)=x^{3}-2 x+2$ com as retas tangentes conforme a variação de $x_{0}=[0,2]$ com incrementos de 0,1

Fonte: Da experiência.

Nesse momento pretendemos fazer um sistema dinâmico no GeoGebra de modo que ele mostre a reta tangente de qualquer gráfico dado com os valores variando conforme a barra deslizante. Para tanto, foi mostrado que o GeoGebra reconhece o comando $f^{\prime}(x)$, portanto basta informarmos o valor de $f(x)$ que o restante será feito de modo dinâmico pelo software, incluindo o gráfico de $f^{\prime}(x)$ e a reta tangente "deslizante" com a equação $y-f\left(x_{0}\right)=f^{\prime}\left(x_{0}\right)\left(x-x_{0}\right)$ conforme Figura 6 .

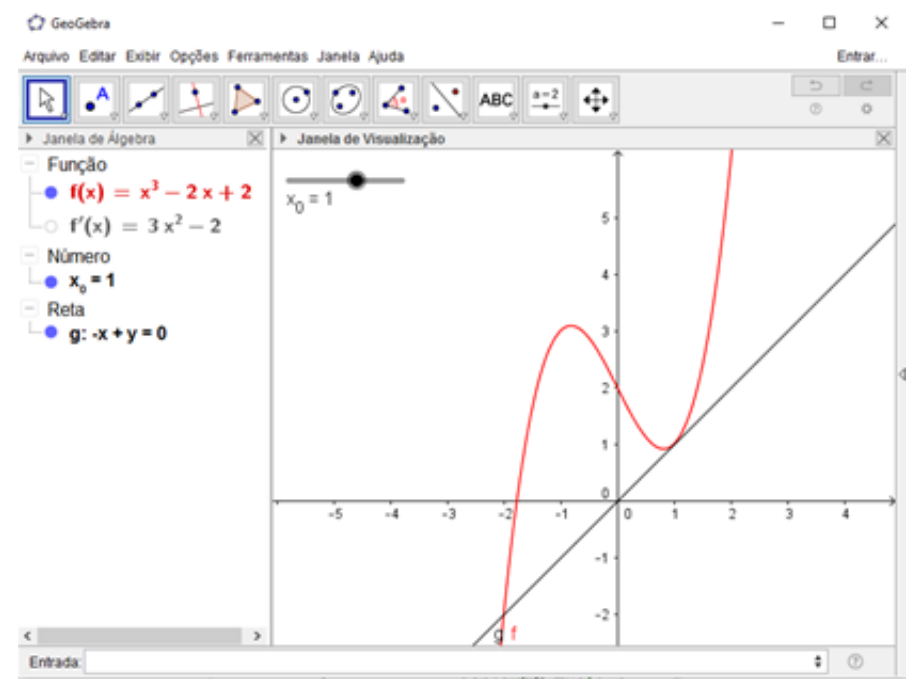

Figura 6 - Plotagem de $f(x)=x^{3}-2 x+2$ com a reta tangente em abscissa 1

Fonte: Da experiência. 
Para uma melhor visualização das retas tangentes "deslizando" no gráfico, ativamos a opção "habilitar rastro" para que a reta tangente deixe um rastro por onde passar, assim possibilitando ver a progressão com incrementos de 0,1. O resultado podemos ver na Figura 7.

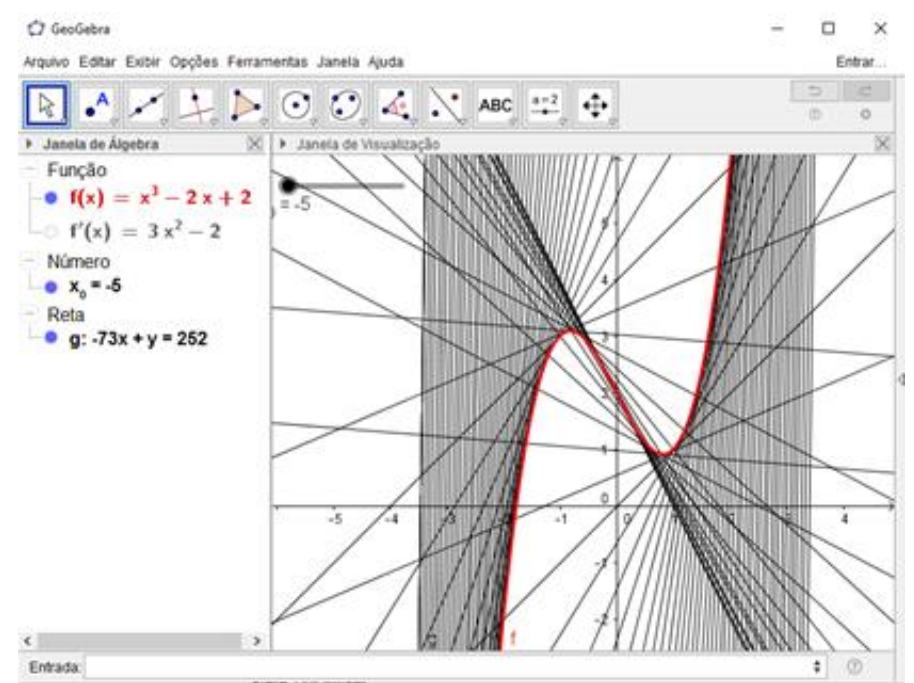

Figura 7 - Plotagem de $f(x)=x^{3}-2 x+2$ com a opção "habilitar rastro" ativado para a reta tangente Fonte: Da experiência.

Para uma última atividade faremos uso de outra ferramenta do GeoGebra, a ferramenta "inclinação" (que está em destaque na Figura 8). Assim colocaremos em uma só aplicação dinâmica no GeoGebra a função primitiva, a função derivada, a reta tangente para o valor de abscissa $x_{0}$, um segmento que representa o valor do coeficiente angular referente ao valor de $f\left(x_{0}\right)$ e a inclinação da reta tangente.

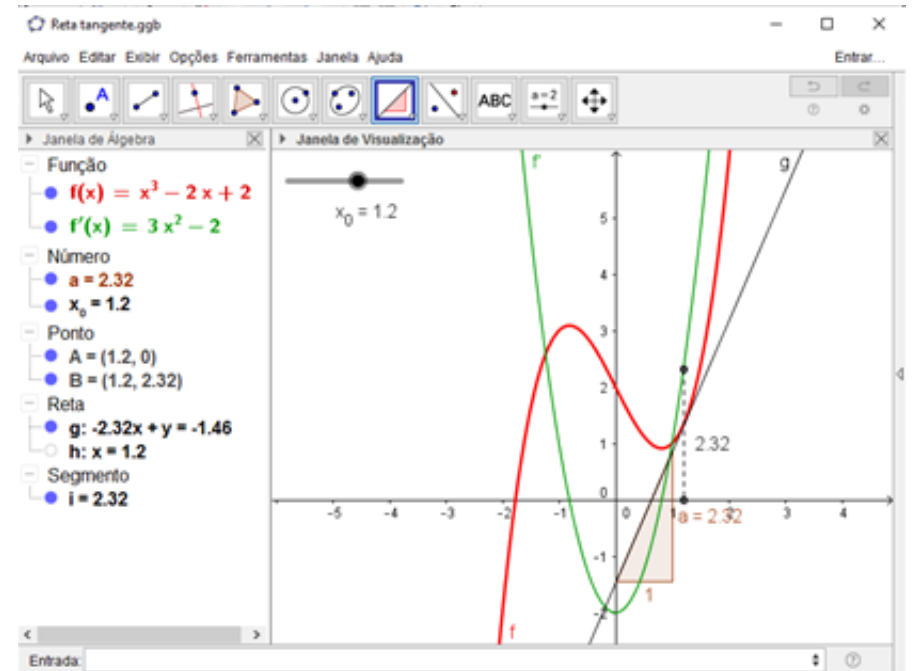

Figura 8 - Plotagem de $f(x)=x^{3}-2 x+2$ com a opção "habilitar rastro" ativado para a reta tangente Fonte: Da experiência.

Nessa última atividade pretendíamos mostrar a relação direta entre a função derivada e o coeficiente angular da reta tangente em cada ponto, fazendo uma ligação direta e perceptível entre o coeficiente angular da reta tangente e o valor de $f^{\prime}\left(x_{0}\right)$. Na Figura 8 os discentes puderam perceber que o gráfico de $f^{\prime}(x)$, em verde, representa a variação do valor do coeficiente e o triângulo retângulo vermelho representa a inclinação 
reta. No caso específico desse exemplo, o valor $f^{\prime}(1,2) \cong 2,32$. Assim deixando claro a relação entre a função derivada e o coeficiente angular da reta tangente a um ponto.

\section{Resultados e discussão}

Durante a execução dos trabalhos, nos foi possível perceber a curiosidade dos discentes ser aguçada diante da interface do GeoGebra no computador. O fato de ser permitido explorarem o software livremente os levou a visualizar algo não os era permitido somente explorado por abstrações e esboços gráficos feitos em seus cadernos. Testaram também colocar funções ao acaso e verificar as relações entre sua derivada.

Durante todo o desenvolvimento da atividade, foram propostas discussões e questionamentos, no sentido de desenvolver o raciocínio construtivo acerca dos conceitos e possibilitar a aprendizagem significativa, pois, concordando com Ausubel (2003), Freire (2000) e Piaget (2003), quando este aponta que a verdadeira trajetória de desenvolvimento do pensamento não vai no sentido do docente para o discente de forma linear, mas tem de ser um conhecimento construído sendo o discente autônomo nesse processo, assim tornando esse conhecimento significativo.

Essa exploração da interação tríade entre discente-TIC-docente faz com que o discente teste os limites e a utilidade de qualquer conteúdo a ser ministrado. Extrapolando os limites do ensino puramente abstrato, trazendo para a cena o concreto onde o discente pode ver, observar, sentir e interagir com o conteúdo matemático que está sendo estudado, que no caso foram as retas tangentes por meio de derivada.

\section{Considerações finais}

Não podemos deixar de enfatizar que existem várias tendências no ensino aprendizagem de matemática tais como: etnomatemática, ludicidade, modelagem, entre outras. Não podemos admitir que o ensino se consolide sempre de forma tradicional e que tanto os discentes quanto os docentes se sintam confortáveis para utilizar alternativas para melhorarmos os resultados na disciplina supracitada.

Não temos o objetivo de defender as TIC como método infalível do ensino aprendizagem de matemática, no entanto procuramos uma alternativa viável para que torne agradável a forma de ensinar e aprender matemática, acreditando assim, na eficiência de sua utilização no processo de ensino e aprendizagem.

Podemos destacar os aspectos positivos no desenvolvimento na atividade proposta, como a interação entre o discente e a interface do software GeoGebra. Percebemos os discentes interessados na construção das parábolas, uma vez que os mesmos construíam os gráficos e percebiam as diferenças no estudo do vértice. Desse modo os discentes se mostraram ativos no processo de ensino e sendo atores principais nesse processo.

Além disso, vale ressaltar que os discentes, motivados pelo uso do software objeto dessa experiência e pela possibilidade de aprimoramento de conceitos já constituídos, mostraram-se participativos e atuantes durante as atividades. Atingindo o objetivo proposto inicialmente, ou seja, compreendendo o conceito de derivada como reta tangente no ponto com mais significado, fato evidenciado na participação destes discentes nas aulas subsequentes, inclusive trabalhando com gráficos de pontos não-deriváveis. 


\section{Referências}

AUSUBEL, D. P. Aquisição e retenção de conhecimentos: uma perspectiva cognitiva. Lisboa: Plátano, 2003.

AUSUBEL, D. P.; NOVAK, J. D.; HANESIAN, H. Psicologia educacional. Tradução de Eva Nick. Rio de Janeiro: Interamericana, 1980.

ÀVILA, G. Limites e derivadas no Ensino Médio? Revista do Professor de Matemática, São Paulo, n. 60, 2006. 30-38.

BALANCHO, M. J.; COELHO, F. M. Motivar os alunos - Criatividade na relação pedagógica: conceitos e práticas. $3^{\mathrm{a}}$. ed. Lisboa: Texto Editora, 2001.

BOYER, C. B. História da matemática. 2a . ed. [S.1.]: Editora Edgard Blücher, 2012.

COSTA, P. O.; JÚNIOR, A. J. D. S. Tecnologia da informação e comunicação no ensino de cálculo. FAMAT em revista, Uberlândia, v. 5, n. 9, 2007. 431-440.

FREIRE, P. Pedagogia da autonomia: saberes necessários à prática educativa. $15^{\mathrm{a}}$. ed. São Paulo: Paz e Terra, 2000.

GRAVINA, M. A.; SANTAROSA, L. Aprendizagem da matemática em ambientes informatizados. Revista Informática na Educação Teoria e Prática, Porto Alegre, 1, 1999.

MELLO, J. C. C. B. S. D.; MELLO, M. H. C. S. D. Integração entre o ensino de cálculo e o de pesquisa operacional. Revista Produção, v. 13, n. 2, 2003. 123-129.

PAGANI, É. M. L.; ALLEVATO, N. S. G. Ensino e aprendizagem de cálculo diferencial e integral: um mapeamento de algumas teses e dissertações produzidas no Brasil. VIDYA, Santa Maria, 34, 2014. 61-74.

PIAGET, J. Seis estudos de psicologia. Tradução de Maria Alice Magalhães D'Amorim e Paulo Sergio Lima Silva. 24ª ed. Rio de Janeiro: Forense Universitária, 2003.

PIAGET, J.; INHELDER, B. A psicologia da criança. Tradução de Octavio Mendes Cajado. 5a . ed. Rio de Janeiro: Difel, 2011.

ROJAS, A.; RITTO, A. C. D. A.; BARBOSA, A. C. C. O software livre para o ensino da matemática em instituições de ensino superior: uma tecnologia social. Cadernos do IME - Série Informática, Rio de Janeiro, v. 25, 2008. 15-26.

SILVA, C. V. D. Modelagem, cálculo e geogebra: uma nova proposta de ensino para funções quadráticas. Palmas: Dissertação de Mestrado - Universidade Federal do Tocantins, 2015.

SOUSA, R. M. D. O uso do geogebra no ensino de função quadrática. Santarém: Dissertação de Mestrado - Universidade Federal do Oeste do Pará, 2014. 